\title{
Musculoskeletal diagnosis
}

\section{S K Misser, MB ChB, FCRad (D) \\ P Mercouris, MB BCh, FF Rad}

Lake Smit and Partners, Durban

Please refer to page 125 of the December 2010 issue of the SAJR (http://www.sajr.org.za/index.php/sajr/article/view/541/412) for the presentation details. We congratulate Dr Himal Gajjar (Schnetler, Corbett and Partners, Cape Town) for a precise and detailed diagnosis, for which he receives an award of R1 000 from the RSSA. Drs Misser and Mercouris elaborate below on the condition and its radiological signs.

\section{Presentation and diagnosis}

The patient, an active hockey player, presented with vague discomfort in the left hip after a hockey game. On questioning, she revealed that she had had a mountain-biking accident a month earlier when she landed on the contralateral hip. After that incident, she had encountered transient hip pain, as though 'she had pulled a muscle'. On examination, minimal clinical abnormality was detected, and the initial orthopaedic impression was that of a labral tear. Plain film and ultrasound examinations were normal.

(Due to space constraints, the images referred to below appear only in the online March 2011 SAJR at www.sajr.org.za.)

MRI demonstrated a chondrolabral tear of the superior labrum (arrow, Fig. 1c) and diffuse thickening and hyperintensity of the ligamentum teres (arrow in Fig. 1a and Fig. 2a) involving both the anterior and posterior bundles. There were no MRI features of bone bruising, femoro-acetabular impingement or femoral head subluxation. Attempted MR arthrography, with resultant extra-articular contrast extravasation, accounts for the increased signal within the left iliopsoas muscle as seen on the axial images (arrow in Fig. 2b). Arthroscopy was performed, confirming the presence of a chondrolabral tear (Fig. 3) and markedly swollen ligamentum teres (grade 2 tear) with extension to involve the foveal attachment site of the ligamentum teres (Fig. 4a). The patient made an excellent return to normal sporting activity 3 months after arthroscopy.

\section{Discussion}

The ligamentum teres, previously described as an unimportant remnant, has recently been found to be an increasingly common abnormal finding at arthroscopy accounting for intractable hip pain in many athletes. The ligament, which is pyramidal in shape, may consist of multiple bundles, and blends with the transverse acetabular ligament. It plays a minor role in (i) maintaining hip stability by reducing excessive movement, (ii) nociception via type iva somatosensory fibres and (iii) minimal femoral head perfusion. ${ }^{1}$

Byrd et al. ${ }^{2}$ reported that ligamentum teres tear (LTT) was the third most common finding at arthroscopy in their series of hip arthroscopy in athletes. Contrary to previous suggestions that LTT was unlikely in the absence of hip dislocation, it has been found to occur in up to three-quarters of cases without associated dislocation. Partial LTT has been described in large arthroscopic series, as a source of disabling pain. ${ }^{3}$ LTT with concomitant labral tear has also been reported. ${ }^{4}$ In this instance, as in the patient reported, the ligamentum teres serves as a secondary stabiliser. When displaced, the disrupted ligamentum teres can result in impingement, especially during hip flexion.

Gray and Villar ${ }^{5}$ classified LTT as follows:

$\begin{array}{lllll}\begin{array}{l}\text { Type } \\ \text { i }\end{array} & \begin{array}{l}\text { Pathology } \\ \text { Complete rupture }\end{array} & \begin{array}{l}\text { Mechanism of injury } \\ \text { Major trauma }\end{array} & \begin{array}{l}\text { Symptoms } \\ \text { Gross instability; inability to } \\ \text { bear weight }\end{array} & \begin{array}{l}\text { Associated pathology } \\ \text { Fractures, labral tears, } \\ \text { chondral damage are common }\end{array} \\ \text { ii } & \text { Partial rupture } & \text { Minor trauma } & \begin{array}{l}\text { Occult instability; pain on } \\ \text { strenuous activity }\end{array} & \begin{array}{l}\text { Occasional labral/chondral } \\ \text { damage; reactive synovitis }\end{array} \\ \text { iii } & \begin{array}{l}\text { Degenerate rupture } \\ \text { (complete or partial) }\end{array} & \text { Chronic attrition } & \text { Pain after prolonged walking } & \text { Commonly osteoarthritis }\end{array}$

(from Bardakos NV, Villar RN. The ligamentum teres of the adult hip. J Bone Joint Surgery 2009;91-B:8-15.)

Impoved arthroscopic techniques and flexible probe development has allowed the surgeon to overcome the difficulty of femoral head sphericity. ${ }^{4}$ Combined with early detection at MRI, arthroscopic access to and debridement of the torn ligament of the femoral head is now much easier, with generally good outcome.

1. Bardakos NV, Villar RN. The ligamentum teres of the adult hip. J Bone Joint Surgery 2009;91-B:8-15,

2. Byrd JWT, Jones KS. Hip arthroscopy in athletes. Clin Sports Med 2001;20:749-762.

3. Rao J, Zhou YX, Villar RN. Injury to the ligamentum teres. Mechanism, findings, and results of treatment. Clin Sports Med 2001;20(4):791-799.

4. Bharam S. Labral tears, extra-articular injuries, and hip arthroscopy in the athlete. Clin Sports Med 2006;25(2):279-292.

5. Gray AJ, Villar RN. The ligamentum teres of the hip: an arthroscopic classification of its pathology. Arthroscopy 1997;13:575-578. 